\title{
Study on Provincial Land Use Database Remittance Standard Establishment
}

\author{
Wenfeng Liao ${ }^{1}$, Shiwu $\mathrm{Xu}^{2}$ \\ ${ }^{1}$ Land Resources Information Center of Guangdong, Guangzhou, China \\ ${ }^{2}$ Faculty of Information Engineering, China University of Geosciences, Wuhan, China \\ E-mail: gzlwf 302@126.com
}

\begin{abstract}
In order to realize county-level land use database remittance, establish the provincial land use database and realize annual change statistics, this paper analyzed the requirements for establishing the provincial land use database remittance standards. It proposed the principle of establish the standard compile, introduced the standard establishment process, described the standard main content, and demonstrated technical reasons for standard topologic relationship, expression method for land use data time dimension, data file naming rule, land use element classification, land use database digital dictionary file composition, land use spatial objects, etc. It provides reference for the standard establishment of provincial land use database remittance.
\end{abstract}

Keywords: Land Use, Database, Remittance, Standard

\section{Introduction}

At present, China is building county-level land use database. The database construction for the national level should adopt software recommended by Ministry of Land and Resources. There are several database construction scales, 1:2000, 1:5000, 1:10000, etc. As database building uses various platforms and various scales, provincial land use database needs to be established to achieve county-level land use database remittance, build provincial land use database and realize annual change statistics. This database should be flexible to change in different software. The standard provincial land use database should set uniform data use feature classification code, layer division, data file naming rule, unified spatial data, attribute data and data dictionary structure, unified conversion format and metadata formats, etc [1].

\section{The Standard Establishment Principle}

Standard building must follow certain principles. Provincial land use database remittance standard establishment principle mainly includes the following.

\subsection{Standard Should Orient to Requirement and Data Result}

The standard orients to data classification, storage, sharing and transfer in routine land use basic data management. It sets common contents, formats and takes the requirements and result data as the description object. This standard doesn't involve in process data and processing method.

\subsection{Standard Independence}

From the data standardization aspect, the standard compile takes data analysis as the core. It starts from management requirement and doesn't base on any current GIS software platform or application software.

\subsection{Standard Sharing}

Standard basic characteristic is sharing, therefore in standard establishment process, the national and provincial norm and stipulation should be taken as the base. As for data expression model, Literature [2] is the reference. As for data expression, literature [1] and provincial related stipulation is taken as base.

\subsection{Scientific and Open Standard Classification}

Data classification changes with data change and the demand development. It requests standard classification has to reflect current situation and meet the requirements. 


\section{Standard Establishment Process}

Provincial land use database remittance standard establishment generally has the following process.

\subsection{Requirements Analysis}

Firstly, analyze the county-level land use database remittance requirement, and fully understand data source complexity. Secondly, fully understand the multiplicity of county land use database that involved the software and hardware platforms, that is, the smallest set can not be used as standard. While it's difficult to achieve can not be divorced from the actual development of the standard, Thirdly, carefully investigate and analyze existing data resources and systems platforms, ensure the standard has nothing to do with software and the connected resource are not affected.

\subsection{Standard Compilation}

According to the standard guidance, set clear stand quotation standard and the integrant part, then divide standard layer, compile the format, and compile the standard (draft).

\subsection{Ask for Standard Comments and Test}

Ask for opinions of standard related department and sectors extensively, then carry out remitted test of different county-level land use database, after continuous revision, and get the final standard.

\subsection{Standard Expert Argumentation}

Standard expert panel discussion was held and will give lots of valuable suggestions for the final revision.

\subsection{Standard Publishing}

Standard publishing is a process for publish, receive and accept. When the Standard has established, the publishing department can hold a release conference, or in website forms. Related department should prepare to explain any related questions to the public.

\section{The Standard Main Content}

The main content of provincial land use database remittance standard includes the following aspects.

\subsection{Scope}

It sets standard main content and applicable scope.

\subsection{Quotation Standard}

Lists the reference and quotation norm and stipulation of national and provincial related standard.

\subsection{Terminology}

Define Standard related special terms and terminology to guide.

\subsection{Land Use Database Remittance Content}

It contains land use features, such as landownership, parcels, line features, and sporadic parcels. It also includes other relevant features such as, land use data processing, management and analysis which mainly include the fundamental geographic features, the administrative region features and the raster features, etc [1].

\subsection{Land Use Database Remittance Form}

Vector data is remitted in standard map sheet or a countylevel administrative region form. Raster data is remitted in standard map sheet form. Land use database data dictionary and metadata is remitted in county-level administrative region form.

\subsection{Land Use Database Remittance Scope}

All features remittance in administrative region. Other features outside the administrative region are not remitted. For initial data remittance, all features will be remitted. When remitted data changes, all the involved features need to change (including additional and unused features).

\subsection{Data Features Classification, Coding and Characterization in Land Use Database}

Because different features have different purposes and usage methods, the land use database data features should be classified management. The larger class is classified in face method, while smaller ones use line classification method [1]. According to different feature characteristics, the land use database data feature are divided into basic geographic information, land use, raster, basic farmland, land ownership and other features [1].

\subsection{Land Use Data File Naming Rule}

Land use data in data use database remittance and data conversion will follow the following naming rules in describing other files, including land use standard map 
sheet data file name rule, and land use data file naming rule based on administrative region [1].

\subsection{Land Use Database Structure}

Give detailed description for the land use database spatial data structure, the attribute structure, the dictionary structure and an attribute code, etc [1].

\subsection{Land Use Database Metadata}

Lists land use database metadata form, define a twodimensional data table for the land use database metadata which contains, data item, data type, value field definition, etc $[1,3,4]$.

\subsection{Land Use spatial Data Conversion Format}

Describe data format content and grammar rule for various data conversion, such as vector data, the raster data, the metadata and the data dictionary $[1,2]$.

\subsection{Appendix}

It includes land use terminology, spatial objects definition, land use vector data transfer format sample, land use database data dictionary transfer format samples and land use database metadata samples, etc.

\section{Technical Description}

Technical description for standard establishment of provincial land use database remittance.

\subsection{Topologic Relationship}

In standard, the description of the topologic relationship, should not only ensure data completeness and consistency, it also should reflect the principle that the standard has nothing to do with platform software. Topologic relationship allows a certain data capacity and requires fully expression of spatial objects. In other words, any face-shaped geometric object should ensure that the coordinate's connection strings are closed. The boundary of different spatial geometric objects is overlapped in spatial position, which needs separate description [2].

\subsection{Land Use Data Time Dimension Representation}

Fully express the historical condition of land use another request for land use data expression. The specific expression form is as follows, firstly, different periods land use data should be completely recorded. This method is intuitive but data is redundancy which is suitable for non-GIS platform management system. Secondly, establish base year background data and record changed data in different time period. In this situation, data redundancy is much smaller and easier to manage. While it needs spatial analysis to completely express land use information which is suitable for GIS platform. As the provincial land use database is based on the GIS platform management system, land use database remittance generally adopts the second method.

\subsection{Data File Naming Rule}

Data file in Standard only refers to remitted and transferred data file. In the process of data collection, processing and management, software usage, application, and management should be consistent with the naming rules. It has to establish conversion rules or procedures with standard naming rules.

\subsection{Land Use Features Classification}

In land use data management, features classification code can use the user-defined code, provided that it has to establish correspondence rule with standard classification code system. It has automated transformation program. What's more, the feature classification should be in accord with the standard.

\subsection{Land Use Database Data Dictionary File Composition}

Land use database data dictionary file usually consists of three parts: the first part is the file header, the second part is the data dictionary structure, and the third one is the data dictionary data.

\subsection{Land Use Spatial Objects}

Land use vector data constitutes by the spatial geometry data and attribute data. The two are connected by specific identification code. Identification codes with the same geometry data and attribute data describes the same space objects. The spatial objects in land use data generally refers to its specific features. Space objects expressed by land use spatial geometry data can be divided into zero-dimensional object, one-dimensional objects and twodimensional objects [1,2] according to their geometry.

\section{Conclusions}

According to the above principle, process, content and method, "Guangdong Province Land Use Database Re- 
mittance Standard” has been formulated and published. This system has also been successfully in Guangdong Province's county level land use database remittance and provincial land use database construction. This system has played important role in administrative land use data management.

\section{References}

[1] The Ministry of Land and Resources P.R.C. TD/T 1016-2007 Standard for Land Use Database, The Ministry of Land and Resources P.R.C, Beijing, 2007.
[2] General Administration of Quality Supervision, Inspection and Quarantine of P.R.C, Standardization Administration of the Peoples Republic of China. GB/T 177982007 Geospatial Data Transfer Format, Standards Press of China, Beijing, 2007.

[3] The Ministry of Land and Resources P.R.C. TD/T 10162003 Core Metadata Standard for Land and Resources Information, The Ministry of Land and Resources P.R.C, Beijing, 2007.

[4] State Bureau of Surveying and Mapping, CH/T 10072001 Metadata for Digital Products of Fundamental Geographic Information, Surveying and Mapping Press, Beijing, 2001. 